\title{
Quality characteristics of fresh beef during storage using cold chain containers
}

\author{
Ki-Hyun Kwon*, Jong-Hoon Kim, Byeong-Sam Kim, Hwan-Soo Cha, \\ Ji-Young Kim, So-Hee Kim \\ Korea Food Research Institute, Seongnam 13539, Korea
}

\section{저온 유통 용기에 따른 소고기의 저장 중 품질평가}

\author{
권기현*·김종훈·김병삼·차환수·김지영·김소희 \\ 한국식품연구원
}

\begin{abstract}
The efficacy of an experimentally designed cold chain container and a currently used styrofoam container was investigated with respect to important factors affecting the quality of fresh beef during storage under different conditions. The temperature in the TEPP-1 container was maintained at $5^{\circ} \mathrm{C}$ using a phase change material (PCM) during transport and delivery. During storage in the TEPP-1 container, no significant difference was observed in pH of beef, but color decreased slightly, which does not affect the desire to purchase. After storage for 7 days, the rate of VBN and TBA in the TEPP-1 container, was lower than that in the TEPP-2 container. Drip loss was lower in the TEPP-1 container $(0.87 \%)$ than in the TEPP-2 container (1.78\%). No significant changes were observed in microbal count until 4 days in either of the containers, but after storage for 7 days, the count increased significantly. Microbial count in TEPP-1 was $6.65 \log \mathrm{CFU} / \mathrm{mL}$ and that in TEPP-2 was $7.62 \mathrm{log} \mathrm{CFU} / \mathrm{mL}$. The results of sensory evaluations indicated that the overall acceptability of beef after storage for 7 days was better in the TEPP-1 container than in the TEPP-2 container. The EPS container was inferior in comparison with TEPP-1 and TEPP-2. It was impossible to continue the experiment using the EPS container after 3 days. These results suggest that the experimentally designed TEPP-1 container can be used for beef transport and delivery for 7 days without significantly affecting the quality of beef.
\end{abstract}

Key words : PCM, pelitier devices, distribution, beef

\section{서 론}

신선식품은 원료 농식품 중 $50 \%$ 이상이며, 식자재 및 식재료를 포함하면 수확 후 관리와 저온 유통 시스템의 적용으로 수출이 증가하는 추세이다. 특히 고품질의 농식 품에 대한 수요가 증가함에 따라 관련 유통기술과 저온 유통시스템 시설 등 관련 산업이 성장하고 있다. 건강하고 안전한 먹거리에 대한 관심이 증대되고 소득 수준의 향상과

*Corresponding author. E-mail : kkh@kfri.re.kr Phone : 82-31-780-9258, Fax : 82-31-780-9144

Received 2 October 2015; Revised 9 November 2015; Accepted 25 November 2015.

Copyright (c) The Korean Society of Food Preservation. All rights reserved.
여성의 경제 활동이 증가함에 따라 신선편이식품의 시장 규모는 성장하고 있다. 그러나 국내 신선식품 유통환경과 인프라의 미비로 품질유지를 위한 효과적인 유통관리가 필요한 실정이다.

다양한 분야에서 에너지의 저장 - 변환 - 이용 기술의 수 요가 증가하고 있으며, 저비용 고효율 에너지 적용 공정은 국내외적으로 수요가 증가할 것으로 예측되며, 식품 분야 에서도 필요할 것으로 판단된다. 그러나 잠열재의 경우 잠 열량, 열전도도, 정압비열, 부피팽창계수 등의 특성과 과냉 각, 상분리, 부식성, 화학적 안전성, 인체 무해 등의 기술적 해소요인이 많아 이를 개선할 수 있는 잠열재의 개발이 요구되며, 가격 경쟁력과 환경 친화적인 물질로 부가가치 를 창출할 수 있도록 기술개발이 이루어져야 한다. 최근 선진국에서는 Peltier effect를 이용한 열전모듈, 펠티어 소 
자, thermoelectric cooler(TEC), thermoelectric module(TEM) 등의 열전소자를 개발하여 heat pump 장치에 사용하여 냉 각 시스템으로 보급되고 있으나 국내는 개발 초기 단계이 다. 다발성 열전재료를 접합 또는 합금하여 신재생 에너지 자원으로 활용하고 있으나, 현재 열전소재의 개발에 관한 많은 연구는 나노기술과 관련된 내용이 주류이다. 현재 국 내에서는 냉 - 난방 시스템, 냉 - 온장 시스템, 정밀 항온유 지 장치, 제습-팬 실용화, 활어 수송용 등으로 부분 연구개 발이 이루어지고 있으나 직 · 간접적으로 수확 후 수·배송 에 관계되는 응용 및 상용화 기술은 전무한 상태이다.

우리나라 한우는 기원전 200여년 전부터 농경과 운반용 으로 사육되어 이용되었으며, 1980 년 대 비육으로 변경되었 다고 한다(1). 조선시대에 설하멱적은 너비아니에서 지금 의 불고기로 발전하였고, 불고기는 세계인이 좋아하는 한 국 음식 중에 하나로 우리나라의 소고기를 이용한 역사이다 (2). 소고기는 등급별로 나누어져 있는데 2004년에 고급화 추세로 인해 등급을 $1^{++}, 1^{+}, 1,2,3$ 등급으로 개정, 고시 되었다(3). Hwang 등(4)의 보고에 따르면 한우의 구매는 연령이 높을수록 많은 것으로 나타났고, 구매 부위는 등심 이 $43.5 \%$ 로 가장 높았고, 갈비(22.9\%), 안심(10.5\%), 양지 (9.9\%) 등의 순으로 조사되었다. 소고기는 대부분이 근육단 백질로 아미노산의 조성은 매우 우수하지만 tryptophan이 부족하여 고구마나 시금치 등과 같은 tryptophan의 함량이 높은 식품과 함께 조리하면 좋다고 한다. 또한 무기질로의 인이 함량이 높아 산성식품에 속한다(5). 포장방법에 따른 냉장 소고기의 이화학적 성질변화(6), 인진쑥을 급여한 한 우육의 특성(7), 쑥 첨가 사료를 섭취한 한우육의 냉장 중 품질 변화(8), 성숙도와 근내지방도가 비육 한우의 육질에 미치는 영향(9) 등 소고기에 대한 연구가 보고되고 있다.

본 연구 이용된 장치는 이동식 수송 컨테이너 및 장치에 잠열 온도 특성이 유지되는 잠열재와 에너지 지속형 열전소 자 장치를 삽입하여 이동이 가능한 축냉 수·배송 시스템을 개발하였다. 이번 실험을 통해 신선식품의 유통에 이용되 고 있는 스티로폼(EPS) 박스와 개발한 수 - 배송용기 $(50 \mathrm{~L}$, $250 \mathrm{~L}$ )에 소고기를 저장하면서 저장 중 품질특성을 조사하 였다.

\section{재료 및 방법}

\section{실험재료 및 저장 조건}

소고기는 하나로마트(서울, 석촌점)에서 구입하여 같은 개체의 소에서 등심부위를 실험에 사용하였으며, 두께 1 $\mathrm{cm}$ 로 각각 개별 포장하여 저장하였다. 수·배송용기 (thermoelertic system)는 지속형 열전소자를 기술을 이용하 여 온도유지가 가능하도록 본 연구원에서 자체 개발, 제작 한 것으로 용량에 따라 TEPP-1 $(250 \mathrm{~L})$ 와 TEPP-2 $(50 \mathrm{~L})$ 로 구분하여 내부 온도가 각각 $5^{\circ} \mathrm{C}$ 가 되도록 작동시킨 후 실험 에 사용하였다. 또한 각각의 수·배송 용기에 일반시중에서 판매되는 축냉팩과 water $60 \%$ 와 n-tetradecane $\left(\mathrm{C}_{14} \mathrm{H}_{30}\right) 40 \%$ 의 비율로 혼합하여 제조한 잠열재((주)FMS, 성남, 한국)를 구분하여 넣고 실험하였고 저장 방법은 총 3 가지로 구별하 였다(Table 1).

\section{온도측정}

온도측정은 Termo Recoder(TR-52, T\&D Co., Nagano, Japan)를 이용하여 온도변화 기록을 측정하였으며, 측정 부위는 잠열재, 수·배송용기 내부, 샘플중심을 각각 측정 하였다.

\section{$\mathrm{pH}$ 및 색도 측정}

소고기의 $\mathrm{pH}$ 측정은 시료 $10 \mathrm{~g}$ 과 증류수 $20 \mathrm{~mL}$ 을 mixer 로 균질화 하고 $\mathrm{pH}$ meter를 이용하여 3 반복하여 측정하였 다. 색변화 측정은 chromameter(CR-200, Minolta Co., Osaka, Japan)을 이용하여 3반복하여 측정하였다.

\section{$\mathrm{VBN}$ 측정}

VBN 측정은 Conway 법을 이용한 미량확산법(10)에 준 해 측정하였다. 시료 $5 \mathrm{~g}$ 에 증류수로 $50 \mathrm{~mL}$ 까지 부피를 맞춰준 후 homogenizer로 균질화 한 다음 여과지(Whatman No.1)로 여과한다. 여과액 $1 \mathrm{~mL}$ 를 conway dish 외실 왼쪽에 넣고 내실엔 $1 \mathrm{~mL}$ 의 $0.005 \mathrm{M} \mathrm{H}_{2} \mathrm{SO}_{4}$ 을 넣은 후 외실 오른쪽 에 포화용액 $\mathrm{K}_{2} \mathrm{CO}_{3}$ 용액 $1 \mathrm{~mL}$ 를 넣는다. 여과액과 $\mathrm{K}_{2} \mathrm{CO}_{3}$ 용액을 잘 섞은 다음 $25^{\circ} \mathrm{C}$ 에서 60 분간 반응 시킨다. 반응

Table 1. Processing conditions for beef quality evaluation

\begin{tabular}{|c|c|c|c|c|c|}
\hline & Cold chain container & Ice-pack number & Ice-pack type & $\begin{array}{l}\text { Thermoelectric } \\
\text { temperature }\left({ }^{\circ} \mathrm{C}\right)\end{array}$ & Storage temperature $\left({ }^{\circ} \mathrm{C}\right)$ \\
\hline $\mathrm{EPS}^{1)}$ & EPS box & $500 * 8$ & Cold storage pack & - & - \\
\hline TEPP $^{22}-1$ & Thermoelectric system $(250 \mathrm{~L})$ & $500 * 15$ & $\mathrm{PCM}^{3)}$ & 5 & 5 \\
\hline TEPP-2 & Thermoelectric system $(50 \mathrm{~L})$ & $500 * 8$ & $\mathrm{PCM}$ & 5 & 5 \\
\hline
\end{tabular}

\footnotetext{
${ }^{1)}$ EPS : Expandable polystyrene.

${ }^{2)}$ TEPP : Thermoelectric expanded polypropylene.

${ }^{3} \mathrm{PCM}$ : Phase change material.
} 
후 내실에 Brunswik 시약으로 발색시킨 후 $0.01 \mathrm{~N} \mathrm{NaOH}$ 로 적정하였다.

\section{TBA 측정}

소고기를 마쇄하여 $10 \mathrm{~g}$ 을 취한 후 $0.3 \%$ BHA $0.5 \mathrm{~mL}$ 넣고 $20 \% \mathrm{TCA}$ 용액 $25 \mathrm{~mL}$ 를 가하여 homogenizer로 균질 화 한 다음 증류수로 $50 \mathrm{~mL}$ 가 되도록 정용한다. 정용한 후 여과지(Whatmain No.1)를 이용하여 여과 후 여과액 5 $\mathrm{mL}$ 와 $5 \mathrm{mM}$ thiobarbituric acid(TBA)용액 $5 \mathrm{~mL}$ 를 가하여 혼합한 후 15 시간 냉암소에 방치한 다음 $530 \mathrm{~nm}$ 에서 흡광 도로 측정하였다.

\section{육즙 손실 측정}

소고기의 육즙 손실(\%) 측정은 조사전과 조사 후의 무게 를 측정하여 계산하였다.

\section{미생물 측정}

총균수 측정은 소고기 표면을 Swab(3M Pipette Swab)을 이용하여 일정 횟수로 문질러 취한 후 단계적으로 희석하여 총균수 측정 배지(Petri film. $3 \mathrm{M}$ Co., Ltd., CA, USA)에 접종하여 $37^{\circ} \mathrm{C}$ 에 배양한 후 $\log \mathrm{CFU} / \mathrm{g}$ 으로 나타내었다.

\section{기호도 조사}

관능평가는 패널 15 명을 선정하여 소고기의 외관, 육색 (선홍색), 지방색(유백색), 이취, 다즙성, 전반적인기호도 항목으로 9점 척도법으로 평가하였다.

\section{통계분석}

통계분석은 SAS program(6.0, SAS Inc., Cary, NC, USA) 을 이용하여 ANOVA analysis와 Duncan's multiple range test 방법으로 시료간의 유의성 $(\mathrm{p}<0.05)$ 을 분석하였다.

\section{결과 및 고찰}

\section{온도변화}

저장 1 일째 EPS box의 잠열재 온도는 $0^{\circ} \mathrm{C}$, 수 - 배송용기 내부는 $17.1^{\circ} \mathrm{C}$, 샘플중심은 $11.3^{\circ} \mathrm{C}$ 로 저장 기간이 지날수록 점차 높아지는 것으로 측정되었다. 저장 2 일째 잠열재, 내 부, 샘플 온도는 각각 $17,20.9,19.3^{\circ} \mathrm{C}$ 로 저장 3 일째에는 잠열재, 내부, 샘플온도가 $25^{\circ} \mathrm{C}$ 이상으로 급격히 높아지는 것으로 측정되었다. 저장기간 동안 EPS box의 평균온도는 잠열재 $8.2^{\circ} \mathrm{C}$, 내부 $20.2^{\circ} \mathrm{C}$, 샘플 $15^{\circ} \mathrm{C}$ 로 측정되었다. TEPP-1 과 TEPP-2는 저장 2 일째 잠열 재는 $2,4^{\circ} \mathrm{C}$, 내부온도는 5 , $7.6^{\circ} \mathrm{C}$, 샘플온도는 $5.5,7.4^{\circ} \mathrm{C}$ 로 측정되었고 저장 7 일째에는 잠열재는 $2,4.5^{\circ} \mathrm{C}$, 내부온도는 $4.5,6.8^{\circ} \mathrm{C}$, 샘플온도는 5.4 , $6.6^{\circ} \mathrm{C}$ 로 TEPP-1이 TEPP-2에 비해 온도가 유지되는 것으로
측정되었다. 저장기간 동안 TEPP-1의 평균온도는 잠열재 $1.8^{\circ} \mathrm{C}$, 내부 $5.1^{\circ} \mathrm{C}$, 샘플 $5.5^{\circ} \mathrm{C}$ 로 측정되었고, TEPP-2는 잠열 재 $3.9^{\circ} \mathrm{C}$, 내부 $6.7^{\circ} \mathrm{C}$, 샘플 $7.1^{\circ} \mathrm{C}$ 로 측정되어 저장기간 동안 수배송용기 TEPP-1가 설정온도 $5^{\circ} \mathrm{C}$ 로 온도유지가 잘 되는 것으로 측정되었다(Fig. 1).
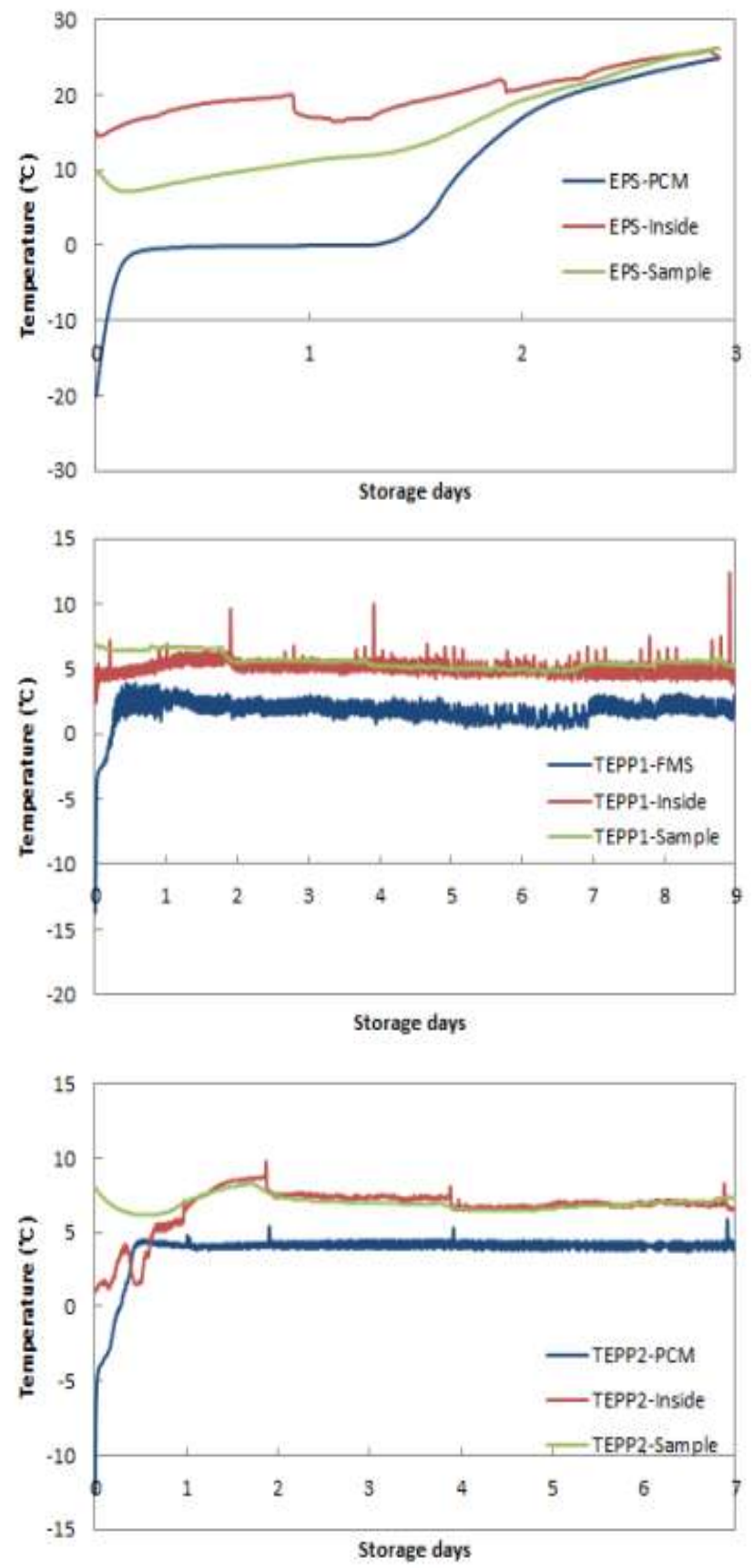

Fig. 1. Changes in temperature of fresh beef during transporting and delivering using cold chain container.

EPS-PCM : Expandable polystyrene-phase change material, EPS-Inside : Expandable polystyrene-inside box temperature, EPS-Sample : Expandable polystyrene-sample core temperature, TEPP1-FMS : Thermoelectric expanded polypropylene-FMS , TEPP1-Inside Thermoelectric expanded polypropylene1-inside box temperature, TEPP1-Sample : Thermoelectric expanded polypropylene1-sample core temperature, TEPP2-PCM Thermoelectric expanded polypropylene2-phase change material, TEPP2-Inside Thermoelectric expanded polypropylene2-inside box temperature, TEPP2-Sample Thermoelectric expanded polypropylene2-sample core temperature. 


\section{$\mathrm{pH}$, 색변화}

수·배송 용기의 저장방법에 따라 소고기 저장 중 $\mathrm{pH}$ 변화는 Table 2 와 같다. 저장 초기 소고기의 $\mathrm{pH}$ 는 5.63으로 측정되었고, 저장 2일에 $\mathrm{EPS}$ 는 $5.78, \mathrm{TEPP}-1$ 는 5.58 , TEPP-2는 5.58로 측정 되었다. EPS는 저장 3일에 5.85로 증가하였고, 더 이상 분석이 불가능 하였다. 저장 7 일에 소고기의 $\mathrm{pH}$ 는 TEPP-1는 5.66로 유의적으로 큰 변화를 보 이지 않은 반면 TEPP-2는 5.94로 저장 초기 보다 유의적으 로 증가한 것으로 나타났다 $(\mathrm{p}<0.05)$. Demeyer 등은 효소에 의한 유리아미노산의 생성과, 숙성 중 단백질의 완충물질 의 변화, 전해질 해리의 감소 및 암모니아의 생성과 아미노 산의 분해로 인하여 저장 중 $\mathrm{pH}$ 가 증가한다고 보고하였다 (11).

소고기의 육색과 지방색은 등급 및 소비자들의 구매에도 중요하고 영향을 준다(9). 저장 방법에 따른 소고기의 저장 중 색변화는 Table 3 과 같이 저장 초기 명도를 나타내는 $\mathrm{L}$ 값은 41.94 value에서 $\mathrm{EPS}$ 는 저장 3일에 37.83 value로 유의적 감소를 보였다 $(\mathrm{p}<0.05) . \mathrm{TEPP}-1$ 는 저장 7 일까지 42.97 value로 증가하는 경향을 보였지만, 저장기간 동안 유의적으로 큰 변화가 없는 것으로 나타났고, TEPP-2는
저장 7일에 40.16 value로 유의적 감소를 보였다. a값은 저장 초기 28.10 value에서 모든 처리구에서 저장 기간이 지날수 록 감소하는 경향을 보였다. EPS는 저장 3일째에 17.57 value로 나타나 소고기의 붉은 색이 크게 감소한 것으로 나타났다. 저장7일에 TEPP-1 23.21, TEPP-2는 16.30 value 로 측정되어 TEPP-1 수배송용기가 소고기의 붉은색이 적 게 변화 된 것으로 나타났다. $\mathrm{b}$ 값 또한 저장 초기 15.00 value에서 EPS는 저장 3일 10.09 value로 유의적으로 점차 감소하였고, 수배송용기 저장구는 저장 7 일째 TEPP-1 13.46, TEPP-2 12.19로 TEPP-1이 가장 적은 감소를 나타냈 다.

\section{VBN, TBA 변화}

$\mathrm{VBN}$ 증가의 원인은 미생물이 분비하는 효소 또는 활성 변화와 관련이 있으며, 저장 중 발생하는 근육 내의 단백질 분해 효소와 미생물이 분비하는 효소들에 의해 근육 단백질 이 아미노산으로 분해되고, 다시 아미노산이 저 분자의 무 기태 질소로 분해되어 $\mathrm{VBN}$ 의 함량이 증가하는 것으로 추 정된다고 Shin 등(12)은 보고하였다. 수·배송용기의 저장 방법에 따라 소고기의 저장 중 $\mathrm{VBN}$ 변화는 저장 초기 7.20

Table 2. Changes in $\mathrm{pH}$ of fresh beef during transport and delivery using cold chain container

\begin{tabular}{ccccccccc}
\hline & & \multicolumn{7}{c}{ Storage period (day) } \\
\cline { 3 - 9 } & Treatment & 0 & 1 & 2 & 3 & 4 & 7 & 9 \\
\hline \multirow{3}{*}{$\mathrm{pH}$} & $\mathrm{EPS}^{1)}$ & $5.63 \pm 0.04^{\mathrm{Ab} 3)}$ & $5.58 \pm 0.09^{\mathrm{Ab}}$ & $5.78 \pm 0.04^{\mathrm{Aa}}$ & $5.85 \pm 0.11^{\mathrm{Aa}}$ & - & - & - \\
& $\mathrm{TEPP}^{2}-1$ & $5.63 \pm 0.04^{\mathrm{Ab}}$ & - & $5.58 \pm 0.04^{\mathrm{Bb}}$ & - & $5.58 \pm 0.05^{\mathrm{Ab}}$ & $5.66 \pm 0.10^{\mathrm{Ab}}$ & $6.00 \pm 0.09^{\mathrm{Aa}}$ \\
& $\mathrm{TEPP}-2$ & $5.63 \pm 0.04^{\mathrm{Ab}}$ & - & $5.58 \pm 0.07^{\mathrm{Bb}}$ & - & $5.54 \pm 0.07^{\mathrm{Ab}}$ & $5.94 \pm 0.16^{\mathrm{Aa}}$ & - \\
\hline
\end{tabular}

${ }^{1)} \mathrm{EPS}$ : Expandable polystyrene.

${ }^{2)}$ TEPP : Thermoelectric expanded polypropylene.

${ }^{3)}$ Means in the same row with different superscripts $(\mathrm{a}-\mathrm{b})$ are significantly different $(\mathrm{p}<0.05)$. Means in the same column with different superscripts $(\mathrm{A}-\mathrm{B})$ are significantly different $(p<0.05)$.

Table 3. Changes in Hunter value of fresh beef during transport and delivery using cold chain container

\begin{tabular}{|c|c|c|c|c|c|c|c|c|}
\hline & \multirow{2}{*}{ Treatment } & \multicolumn{7}{|c|}{ Storage period (day) } \\
\hline & & 0 & 1 & 2 & 3 & 4 & 7 & 9 \\
\hline \multirow{3}{*}{$\mathrm{L}$} & $\mathrm{EPS}^{1)}$ & $41.94 \pm 3.31^{\mathrm{Aa} 3)}$ & $38.31 \pm 3.47^{\mathrm{Ab}}$ & $38.46 \pm 3.04^{\mathrm{Bb}}$ & $37.83 \pm 3.10^{\mathrm{Ab}}$ & - & - & - \\
\hline & TEPP $^{2)}-1$ & $41.94 \pm 3.31^{\mathrm{Aa}}$ & - & $43.06 \pm 4.84^{\mathrm{Aa}}$ & - & $40.01 \pm 5.85^{\mathrm{Aa}}$ & $42.97 \pm 3.99^{\mathrm{Aa}}$ & $42.13 \pm 3.54^{\mathrm{Aa}}$ \\
\hline & TEPP-2 & $41.94 \pm 3.31^{\mathrm{Aab}}$ & - & $41.83 \pm 5.14^{\mathrm{ABab}}$ & - & $44.43 \pm 3.97^{\mathrm{Aa}}$ & $40.16 \pm 2.45^{\mathrm{Ab}}$ & - \\
\hline \multirow{3}{*}{$\mathrm{a}$} & EPS & $28.10 \pm 3.11^{\mathrm{Aa}}$ & $24.23 \pm 2.78^{\mathrm{Ab}}$ & $17.74 \pm 3.51^{\mathrm{Bc}}$ & $17.57 \pm 2.86^{\mathrm{Ac}}$ & - & - & - \\
\hline & TEPP-1 & $28.10 \pm 3.11^{\mathrm{Aa}}$ & - & $24.31 \pm 2.03^{\mathrm{Aabc}}$ & - & $25.52 \pm 3.92^{\mathrm{Aab}}$ & $23.21 \pm 5.20^{\mathrm{Abc}}$ & $21.13 \pm 4.48^{\mathrm{Ac}}$ \\
\hline & TEPP-2 & $28.10 \pm 3.11^{\mathrm{Aa}}$ & - & $25.28 \pm 2.16^{\mathrm{Aa}}$ & - & $25.64 \pm 3.99^{\mathrm{Aa}}$ & $16.30 \pm 3.45^{\mathrm{Bb}}$ & - \\
\hline \multirow{3}{*}{$\mathrm{b}$} & EPS & $15.00 \pm 1.14^{\mathrm{Aa}}$ & $12.68 \pm 0.97^{\mathrm{Ab}}$ & $10.51 \pm 1.27^{\mathrm{Bc}}$ & $10.09 \pm 1.72^{\mathrm{Ac}}$ & - & - & - \\
\hline & TEPP-1 & $15.00 \pm 1.14^{\mathrm{Aa}}$ & - & $13.74 \pm 1.27^{\mathrm{Aab}}$ & - & $13.41 \pm 1.73^{\mathrm{Ab}}$ & $13.46 \pm 1.42^{\mathrm{Ab}}$ & $13.24 \pm 1.19^{\mathrm{Ab}}$ \\
\hline & TEPP-2 & $15.00 \pm 1.14^{\mathrm{Aa}}$ & - & $14.17 \pm 1.11^{\mathrm{Aa}}$ & - & $14.52 \pm 1.03^{\mathrm{Aa}}$ & $12.19 \pm 1.28^{\mathrm{Ab}}$ & - \\
\hline
\end{tabular}

${ }^{1)}$ EPS : Expandable polystyrene.

${ }^{2)}$ TEPP : Thermoelectric expanded polypropylene.

${ }^{3)}$ Means in the same row with different superscripts $(\mathrm{a}-\mathrm{c})$ are significantly different $(\mathrm{p}<0.05)$. Means in the same column with different superscripts $(\mathrm{A}-\mathrm{B})$ are significantly different $(\mathrm{p}<0.05)$. 
$\mathrm{mg} \%$ 로 측정되었고, 저장기간이 지날수록 모든 처리구에 서 유의적으로 점차 증가하는 경향을 보였다(Table 4). 저장 2 일에 EPS는 $11.53 \mathrm{mg} \%$ 로 유의적으로 크게 증가한 반면 TEPP-1, TEPP-2는 각각 7.90, $7.50 \mathrm{mg} \%$ 으로 큰 변화를 보이 지 않았다. EPS는 저장 3 일 이후 부패로 인해 분석이 불가능 하였고, 저장 7일에 TEPP-1은 $8.39 \mathrm{mg} \%$ 로 유의적으로 적은 증가율을 보인 반면 TEPP-2 $15.02 \mathrm{mg} \%$ 로 VBN 함량이 크게 증가한 것으로 측정되었고, 외관과 냄새에서 관능적 으로 부패된 것으로 보였다( $\mathrm{p}<0.05)$. 식품공전(10)에서 식 육에 한해 규정한 수치는 $20 \mathrm{mg} \%$ 이하로 규정되어 있지만, Byun 등(13)은 VBN 함량이 $18 \mathrm{mg} \%$ 이상에서 부패취와 외관에서 관능적 부패가 인정된다고 하였다.
저장 중 TBA 변화는 저장 초기 $0.1940 \mathrm{mgMA} / \mathrm{kg}$ 에서 EPS는 저장 1 일에 $0.4930,3$ 일에 $1.4338 \mathrm{mgMA} / \mathrm{kg}$ 으로 유의 적으로 급격히 증가하는 경향을 보였고( $\mathrm{p}<0.05)$, 나머지 처 리구는 저장 4 일까지 $0.4 \mathrm{mgMA} / \mathrm{kg}$ 이하의 $\mathrm{TBA}$ 를 나타내 었다. EPS 저장 소고기는 3 일 이후 실험이 불가능 하게 부패하였고, 저장 7일에 TEPP-1은 $1.1681 \mathrm{mgMA} / \mathrm{kg}$, TEPP-2는 $1.7396 \mathrm{mgMA} / \mathrm{kg}$ 으로 TEPP-1가 적은 변화를 보 였다. 즉, 휘발성염기질소(VBN)과 지방산패도(TBA) 값의 결과를 통해 TEPP-1가 TEPP-2 보다 소고기의 신선도를 잘 유지하는 것으로 나타났다.

Table 4. Changes in VBN of fresh beef during transport and delivery using cold chain container

(mg\%)

\begin{tabular}{ccccccccc}
\hline & & \multicolumn{7}{c}{ Storage period (day) } \\
\cline { 3 - 9 } & Treatment & 0 & 1 & 2 & 3 & 4 & 7 & 9 \\
\hline \multirow{4}{*}{ VBN } & EPS $^{1)}$ & $7.20 \pm 0.72^{\mathrm{Ab} 3)}$ & $8.78 \pm 1.20^{\mathrm{Ab}}$ & $11.53 \pm 1.38^{\mathrm{Aa}}$ & $13.52 \pm 2.62^{\mathrm{Aa}}$ & - & - & - \\
& TEPP $^{2)}-1$ & $7.20 \pm 0.72^{\mathrm{Ab}}$ & - & $7.90 \pm 0.29^{\mathrm{Bb}}$ & - & $8.08 \pm 0.48^{\mathrm{Ab}}$ & $8.39 \pm 0.47^{\mathrm{Bb}}$ & $13.76 \pm 2.97^{\mathrm{Aa}}$ \\
& TEPP-2 & $7.20 \pm 0.72^{\mathrm{Ab}}$ & - & $7.50 \pm 0.44^{\mathrm{Bb}}$ & - & $8.09 \pm 0.27^{\mathrm{Ab}}$ & $15.02 \pm 0.42^{\mathrm{Aa}}$ & - \\
\hline
\end{tabular}

${ }^{1)}$ EPS : Expandable polystyrene.

${ }^{2)}$ TEPP : Thermoelectric expanded polypropylene.

${ }^{3)}$ Means in the same row with different superscripts $(\mathrm{a}-\mathrm{b})$ are significantly different $(\mathrm{p}<0.05)$. Means in the same column with different superscripts $(\mathrm{A}-\mathrm{B})$ are significantly different $(\mathrm{p}<0.05)$.

Table 5. Changes in hunter value of fresh beef during transport and delivery using cold chain container

$(\mathrm{mgMA} / \mathrm{kg})$

\begin{tabular}{ccccccccc}
\hline & \multirow{8}{c}{ Storage period (day) } \\
\cline { 3 - 9 } & Treatment & 0 & 1 & 2 & 3 & 4 & 7 & 9 \\
\hline \multirow{3}{*}{ TBA } & EPS $^{1)}$ & $\left.0.1940 \pm 0.02^{\mathrm{Ad} 3}\right)$ & $0.4930 \pm 0.05^{\mathrm{Ac}}$ & $1.1542 \pm 0.16^{\mathrm{Ab}}$ & $1.4338 \pm 0.09^{\mathrm{Aa}}$ & - & - & - \\
& TEPP $^{2)}-1$ & $0.1940 \pm 0.02^{\mathrm{Ab}}$ & - & $0.2572 \pm 0.05^{\mathrm{Bb}}$ & - & $0.3451 \pm 0.08^{\mathrm{Ab}}$ & $1.1681 \pm 0.39^{\mathrm{Aa}}$ & $1.2000 \pm 0.07^{\mathrm{Aa}}$ \\
& TEPP-2 & $0.1940 \pm 0.02^{\mathrm{Ac}}$ & - & $0.3612 \pm 0.06^{\mathrm{Bb}}$ & - & $0.3936 \pm 0.07^{\mathrm{Ab}}$ & $1.7396 \pm 0.15^{\mathrm{Aa}}$ & - \\
\hline
\end{tabular}

${ }^{1)}$ EPS : Expandable polystyrene.

${ }^{2)}$ TEPP : Thermoelectric expanded polypropylene.

${ }^{3)}$ Means in the same row with different superscripts $(\mathrm{a}-\mathrm{c})$ are significantly different $(\mathrm{p}<0.05)$. Means in the same column with different superscripts $(\mathrm{A}-\mathrm{B})$ are significantly different $(\mathrm{p}<0.05)$.

Table 6. Changes in drip loss of fresh beef during transport and delivery using cold chain container

$(\%)$

\begin{tabular}{lcccccccc}
\hline & \multirow{8}{c}{ Storage period (day) } \\
\cline { 3 - 8 } & Treatment & 0 & 1 & 2 & 3 & 4 & 7 & 9 \\
\hline \multirow{3}{*}{$\begin{array}{c}\text { Drip } \\
\text { loss }\end{array}$} & EPS $^{1)}$ & $0.64 \pm 0.28^{\mathrm{Aaal}}$ & $0.97 \pm 0.12^{\mathrm{Aa}}$ & $1.44 \pm 0.62^{\mathrm{Aa}}$ & $3.40 \pm 0.79^{\mathrm{Ab}}$ & - & - & - \\
& $\mathrm{TEPP}^{2}-1$ & $0.64 \pm 0.28^{\mathrm{Aa}}$ & - & $0.69 \pm 0.34^{\mathrm{Aa}}$ & - & $0.91 \pm 0.96^{\mathrm{Aa}}$ & $0.87 \pm 0.27^{\mathrm{Ba}}$ & $1.76 \pm 0.71^{\mathrm{Aa}}$ \\
& TEPP-2 & $0.64 \pm 0.28^{\mathrm{Ab}}$ & - & $0.75 \pm 0.26^{\mathrm{Ab}}$ & - & $1.34 \pm 0.41^{\mathrm{Aab}}$ & $1.78 \pm 0.45^{\mathrm{Aa}}$ & - \\
\hline
\end{tabular}

${ }^{1)}$ EPS : Expandable polystyrene.

${ }^{2)}$ TEPP : Thermoelectric expanded polypropylene.

${ }^{3)}$ Means in the same row with different superscripts $(a-b)$ are significantly different $(\mathrm{p}<0.05)$. Means in the same column with different superscripts $(A-B)$ are significantly different $(\mathrm{p}<0.05)$. 


\section{육즙손실}

저장 수·배송용기에 따른 소고기의 육즙손실을 측정 결과는 Table 6과 같다. 저장기간이 지날수록 모든 실험구 에서 육즙손실율은 증가하는 경향을 보였고, 저장 초기 소 고기의 육즙은 $0.64 \%$ 로 측정되었고, 저장 2 일에 $\mathrm{EPS}$ 박스 는 $1.44 \%$ 로 가장 큰 육즙손실을 나타낸 반면 나머지 처리구 (TEPP-1, TEPP-2)는 $0.65-0.75 \%$ 로 손실이 적은 것으로 측 정되었다. 저장 3 일 $\mathrm{EPS}$ 는 $3.40 \%$ 로 유의적으로 큰 육즙손 실이 있었고, 4 일째 TEPP-1은 $0.91 \%$, TEPP-2는 $1.34 \%$ 로
TEPP-1이 유의적으로 적은 손실을 보였다 $(\mathrm{p}<0.05)$. 저장 7 일에 TEPP-1은 $0.87 \%$ 로 큰 변화가 발생하지 않은 반면 TEPP-2는 $1.78 \%$ 육즙 손실을 나타내었다. Jeong과 Lee(3) 는 고급 및 저급 소고기를 저장하면서 측정한 결과 저장기 간이 지날수록 손실율은 증가하였고, 저장 7일째 각각 2.07 , $2.91 \%$ 의 육즙손실이 발생하였다고 보고하였다. 또한 이는 육즙손실의 경우 근내지방도가 높을수록 적게 나타난다고 하였는데, 본 실험보다 육즙손실이 더 큰 것으로 나타난 것은 그러한 원인에 인한 것으로 판단된다.

Table 7. Changes in microbial count of fresh beef during transport and delivery using cold chain container

\begin{tabular}{|c|c|c|c|c|c|c|c|c|}
\hline & & & & & & & & (Log CFU) \\
\hline & \multirow{2}{*}{ Treatment } & \multicolumn{7}{|c|}{ Storage period (day) } \\
\hline & & 0 & 1 & 2 & 3 & 4 & 7 & 9 \\
\hline \multirow{3}{*}{$\begin{array}{c}\text { Total } \\
\text { bacterial } \\
\text { counts }\end{array}$} & $\mathrm{EPS}^{1)}$ & $3.47 \pm 0.18^{\mathrm{Ad} 3)}$ & $3.81 \pm 0.15^{\mathrm{Ac}}$ & $7.03 \pm 0.03^{\mathrm{Ab}}$ & $8.13 \pm 0.07^{\mathrm{Aa}}$ & - & - & - \\
\hline & TEPP ${ }^{2)}-1$ & $3.47 \pm 0.18^{\mathrm{Ab}}$ & - & $3.85 \pm 0.12^{\mathrm{Bb}}$ & - & $4.08 \pm 0.14^{\mathrm{Ab}}$ & $6.65 \pm 0.35^{\mathrm{Ba}}$ & $6.89 \pm 0.70^{\mathrm{Aa}}$ \\
\hline & TEPP-2 & $3.47 \pm 0.18^{\mathrm{Ac}}$ & - & $3.85 \pm 0.11^{\mathrm{Bb}}$ & - & $3.97 \pm 0.06^{\mathrm{Ab}}$ & $7.62 \pm 0.21^{\mathrm{Aa}}$ & - \\
\hline
\end{tabular}

${ }^{1)}$ EPS : Expandable polystyrene.

${ }^{2)}$ TEPP : Thermoelectric expanded polypropylene.

${ }^{3)}$ Means in the same row with different superscripts (a-c) are significantly different $(\mathrm{p}<0.05)$. Means in the same column with different superscripts $(\mathrm{A}-\mathrm{B})$ are significantly different $(\mathrm{p}<0.05)$.

Table 8. Changes in sensory properties of fresh beef during transport and delivery using cold chain container

\begin{tabular}{|c|c|c|c|c|c|c|c|c|}
\hline \multirow{2}{*}{ Items } & \multirow{2}{*}{ Treatment } & \multicolumn{7}{|c|}{ Storage period (day) } \\
\hline & & 0 & 1 & 2 & 3 & 4 & 7 & 9 \\
\hline \multirow{3}{*}{ Appearance } & $\mathrm{EPS}^{1)}$ & $9.0 \pm 0.00^{\mathrm{A} a 3)}$ & $8.6 \pm 0.52^{\mathrm{Aa}}$ & $3.7 \pm 1.25^{\mathrm{Bb}}$ & $1.5 \pm 0.97^{\mathrm{Ac}}$ & - & - & - \\
\hline & $\mathrm{TEPP}^{2)}-1$ & $9.0 \pm 0.00^{\mathrm{Aa}}$ & - & $8.3 \pm 0.67^{\mathrm{Aa}}$ & - & $6.7 \pm 0.82^{\mathrm{Bb}}$ & $5.9 \pm 0.57^{\mathrm{Ac}}$ & $2.6 \pm 1.43^{\mathrm{Ad}}$ \\
\hline & TEPP-2 & $9.0 \pm 0.00^{\mathrm{Aa}}$ & - & $8.3 \pm 1.06^{\mathrm{Aab}}$ & - & $7.6 \pm 0.70^{\mathrm{Ab}}$ & $2.8 \pm 0.92^{\mathrm{Bc}}$ & - \\
\hline \multirow{3}{*}{ Meat color } & $\mathrm{EPS}^{1)}$ & $9.0 \pm 0.00^{\mathrm{Aa}}$ & $8.6 \pm 0.52^{\mathrm{Aa}}$ & $3.7 \pm 1.34^{\mathrm{Bb}}$ & $1.6 \pm 1.07^{\mathrm{Ac}}$ & - & - & - \\
\hline & $\mathrm{TEPP}^{2)}-1$ & $9.0 \pm 0.00^{\mathrm{Aa}}$ & - & $8.3 \pm 0.67^{\mathrm{Aa}}$ & - & $6.6 \pm 0.97^{\mathrm{Bb}}$ & $6.0 \pm 0.82^{\mathrm{Ab}}$ & $2.6 \pm 1.43^{\mathrm{Ac}}$ \\
\hline & TEPP-2 & $9.0 \pm 0.00^{\mathrm{Aa}}$ & - & $8.4 \pm 0.97^{\mathrm{Aab}}$ & - & $8.0 \pm 0.47^{\mathrm{Ab}}$ & $2.4 \pm 1.17^{\mathrm{Bc}}$ & - \\
\hline \multirow{3}{*}{ Fat color } & $\mathrm{EPS}^{1)}$ & $9.0 \pm 0.00^{\mathrm{Aa}}$ & $8.4 \pm 0.52^{\mathrm{Aa}}$ & $4.4 \pm 1.71^{\mathrm{Bb}}$ & $1.4 \pm 0.84^{\mathrm{Ac}}$ & - & - & - \\
\hline & TEPP ${ }^{2)}-1$ & $9.0 \pm 0.00^{\mathrm{Aa}}$ & - & $8.0 \pm 1.15^{\mathrm{Aa}}$ & - & $6.9 \pm 0.74^{\mathrm{Bb}}$ & $6.2 \pm 1.40^{\mathrm{Ab}}$ & $3.1 \pm 1.85^{\mathrm{Ac}}$ \\
\hline & TEPP-2 & $9.0 \pm 0.00^{\mathrm{Aa}}$ & - & $8.2 \pm 1.32^{\mathrm{Aa}}$ & - & $8.1 \pm 0.32^{\mathrm{Aa}}$ & $2.1 \pm 1.73^{\mathrm{Bb}}$ & - \\
\hline \multirow{3}{*}{ Off-flavor } & $\mathrm{EPS}^{1)}$ & $9.0 \pm 0.00^{\mathrm{Aa}}$ & $8.5 \pm 0.53^{\mathrm{Aa}}$ & $3.4 \pm 2.01^{\mathrm{Bb}}$ & $1.1 \pm 0.32^{\mathrm{Ac}}$ & & - & - \\
\hline & $\mathrm{TEPP}^{2)}-1$ & $9.0 \pm 0.00^{\mathrm{Aa}}$ & - & $8.4 \pm 0.70^{\mathrm{Aa}}$ & - & $6.7 \pm 1.06^{\mathrm{Bb}}$ & $5.2 \pm 1.69^{\mathrm{Ac}}$ & $2.3 \pm 1.25^{\mathrm{Ad}}$ \\
\hline & TEPP-2 & $9.0 \pm 0.00^{\mathrm{Aa}}$ & - & $8.1 \pm 1.29^{\mathrm{Ab}}$ & - & $8.0 \pm 0.67^{\mathrm{Ab}}$ & $1.7 \pm 1.34^{\mathrm{Bc}}$ & - \\
\hline \multirow{3}{*}{ Juiciness } & $\mathrm{EPS}^{1)}$ & $9.0 \pm 0.00^{\mathrm{Aa}}$ & $8.4 \pm 0.70^{\mathrm{Aa}}$ & $5.4 \pm 2.27^{\mathrm{Bb}}$ & $1.9 \pm 1.45^{\mathrm{Ac}}$ & - & - & - \\
\hline & $\mathrm{TEPP}^{2)}-1$ & $9.0 \pm 0.00^{\mathrm{Aa}}$ & - & $8.5 \pm 0.71^{\mathrm{Aa}}$ & - & $6.8 \pm 0.92^{\mathrm{Bb}}$ & $6.4 \pm 0.70^{\mathrm{Ab}}$ & $4.4 \pm 2.37^{\mathrm{Ac}}$ \\
\hline & TEPP-2 & $9.0 \pm 0.00^{\mathrm{Aa}}$ & - & $8.4 \pm 0.97^{\mathrm{Aa}}$ & - & $8.0 \pm 1.25^{\mathrm{Aa}}$ & $3.3 \pm 2.06^{\mathrm{Bb}}$ & - \\
\hline \multirow{3}{*}{$\begin{array}{c}\text { Overall } \\
\text { acceptability }\end{array}$} & $\mathrm{EPS}^{1)}$ & $9.0 \pm 0.00^{\mathrm{Aa}}$ & $8.5 \pm 0.53^{\mathrm{Aa}}$ & $3.1 \pm 1.66^{\mathrm{Bb}}$ & $1.2 \pm 0.42^{\mathrm{Ac}}$ & - & - & - \\
\hline & $\mathrm{TEPP}^{2)}-1$ & $9.0 \pm 0.00^{\mathrm{Aa}}$ & - & $8.4 \pm 0.70^{\mathrm{Aa}}$ & - & $6.4 \pm 0.84^{\mathrm{Bb}}$ & $6.3 \pm 1.06^{\mathrm{Ab}}$ & $2.2 \pm 1.23^{\mathrm{Ac}}$ \\
\hline & TEPP-2 & $9.0 \pm 0.00^{\mathrm{Aa}}$ & - & $8.3 \pm 1.06^{\mathrm{Aab}}$ & - & $7.8 \pm 1.03^{\mathrm{Ab}}$ & $2.1 \pm 1.29^{\mathrm{Bc}}$ & - \\
\hline
\end{tabular}

${ }^{1)}$ EPS : Expandable polystyrene.

${ }^{2)}$ TEPP : Thermoelectric expanded polypropylene.

${ }^{3)}$ Means in the same row with different superscripts $(\mathrm{a}-\mathrm{d})$ are significantly different $(\mathrm{p}<0.05)$. Means in the same column with different superscripts $(\mathrm{A}-\mathrm{B})$ are significantly different $(\mathrm{p}<0.05)$. 


\section{미생물 변화}

소고기의 저장 중 미생물 변화는 Table 7에 나타낸 것과 같다. 식육의 미생물은 부패의 원인이 되는 것으로 품질을 유지, 향상시키기 위해 저장기간 중 미생물의 증식을 억제 시켜야 한다(1). 저장 초기 총균수는 $3.47 \log \mathrm{CFU} / \mathrm{g}$ 로 측정 되고, 저장기간이 지남에 따라 모든 처리구의 미생물 증식 은 유의적으로 증가하였다. 저장 2일에 EPS는 $7.03 \mathrm{log}$ $\mathrm{CFU} / \mathrm{g}$ 로 증식하여 부패가 발생 하였음을 알 수 있었고, TEPP-1, TEPP-2는 $3.85 \log \mathrm{CFU} / \mathrm{g}$ 로 유의적으로 변화가 없는 것으로 나타났다( $\mathrm{p}<0.05)$. 저장 4 일에 TEPP-1, TEPP-2 는 각각 $4.08,3.97 \log \mathrm{CFU} / \mathrm{g}$ 으로 유의적 차이는 없었고, 저장 7일째 TEPP-1 $6.65 \log$ CFU/g, TEPP-2는 $7.62 \mathrm{log}$ $\mathrm{CFU} / \mathrm{g}$ 로 증식하여 TEPP-1 수·배송 용기의 저장한 소고기 가 TEPP-2 용기에 비해 미생물이 적게 증식한 것으로 측정 되었다.

\section{기호도 조사}

수배송용기에 따른 저장 기간 동안 소고기의 기호도 조 사는 Table 8에 나타내었다. 외관의 경우 저장 초기에 비해 모두 유의적으로 낮은 점수를 받았고, EPS는 저장 2일에 3.7점으로 상품성을 상실하였다. TEPP-1과 TEPP-2는 저장 4일 각각 6.7, 7.6점의 평가를 받았고, 저장 7일째 TEPP-1은 5.9 점으로 가장 높은 평가를 받은 반면 TEPP-2는 2.8점으로 낮은 평가를 받았으며, 육색 항목 또한 유사한 평가를 보였 다. 육류의 근육내 지방 부분의 색을 비교해 보았을때 노랗 지 않은 것을 소비자가들이 선호하는데 이는 지방의 산패에 관련이 있다고 한다(14). 지방색 항목은 저장 2일째 TEPP-1, TEPP-2 모두 8.0점 이상의 높은 평가를 받았고, 저장 4일에 TEPP-2(8.0점)는 유의적 큰 변화 없이 유지하였고, TEPP-1 은 6.9점으로 TEPP-2에 비해 조금 낮은 평가를 받았다. 하지 만 저장 7일에 TEPP-1은 6.2점을 받은 반면 TEPP-2는 2.1점 으로 평가를 받아 유의적 차이가 나타났다 $(\mathrm{p}<0.05)$. 이취와 다즙성 항목에서도 TEPP-1이 더 좋은 평가를 받았고, 전반 적인 기호도에서도 저장 7일 TEPP-1 6.3점, TEPP-2 2.1점으 로 유의적으로 차이를 나타내는 평가를 받았다. 즉 저장 7 일까지 TEPP-1은 대부분의 항목에서 6.5 점 이상의 평가를 받았지만 TEPP-2는 3점 이하의 평가를 받아 소고기가 부패 되어 상품성이 상실된 것으로 판단되었다.

\section{요 약}

개발한 수배송용기[TEPP-1(250 L), TEPP-2(50 L)]와 기 존의 사용되고 있는 스티로폼(EPS) 박스에 소고기를 저장 하면서 저장 중 품질특성을 조사하였다. 잠열재, 용기내부, 샘플중심의 온도변화 측정에서 저장기간 동안 수배송용기 $\mathrm{TEPP}-1$ 가 설정온도 $5^{\circ} \mathrm{C}$ 로 온도유지가 잘 되는 것으로 측정
되었고, $\mathrm{pH}$ 변화 또한 유의적으로 큰 변화 없이 유지하는 경향을 보였다. 소고기 구매에 영향을 주는 색변화는 TEPP-1에 저장 시 가장 적었고, $\mathrm{VBN}$ 은 저장 7일에 8.39 $\mathrm{mg} \%$ 로 유의적으로 가장 적은 증가율을 나타내었고, TBA 역시 TEPP-2보다 적게 증가하는 것으로 측정되었다. 육즙 손실은 저장 7 일에 TEPP- 1 은 $0.87 \%$ 로 큰 변화가 발생하지 않은 반면 TEPP-2는 $1.78 \%$ 육즙 손실을 나타내었고, 미생 물의 변화는 저장 4 일까지 두 수 · 배송용기의 유의적 차이 는 없었으나 저장 7일에 TEPP-1 $6.65 \log \mathrm{CFU} / \mathrm{mL}, \mathrm{TEPP}-2$ 는 $7.62 \log \mathrm{CFU} / \mathrm{mL}$ 로 증식하여 유의적 차이를 나타내었 다. 기호도 조사 또한 저장 7일째 TEPP-1은 대부분의 항목 에서 6.5점 이상의 평가를 받았지만 TEPP-2는 3점 이하의 평가를 받아 소고기가 부패되어 상품성이 상실된 것으로 판단되었다. EPS 박스는 저장 3일 이후 더 이상 실험이 불가능하였고, 모든 분석항목에서 TEPP-1 $(250 \mathrm{~L})$ 수 · 배송 용기가 TEPP-2 $(50 \mathrm{~L})$ 보다 소고기 신선도 유지에 효과적인 것으로 측정되었고, 저장 7 일까지 소고기의 신선도 유지가 가능한 것으로 판단된다.

\section{References}

1. Seol KH, Kim KH, Kim YH, Youm KE, Lee MH (2014) Effect of temperature and relative humidity in refrigerator on quality traits and storage characterist of pre-packed Hanwoo loin. CNU J Agric Sci, 41, 415-424

2. Kim SW, Cha GH (2015) Study on dietary usage and prohibition on beef in Joseon dynasty. J Korean Soc Food Cult, 30, 64-76

3. Jeong GG, Park NY, Lee SH (2006) Quality characteristics of high and low grade Hanwoo beef during storage at $1{ }^{\circ} \mathrm{C}$. Korean J Food Sci Technol, 38, 10-15

4. Hwang EG, Bae MJ, Kim BK (2010) Research on consumers purchasing characteristics and satisfaction for Hanwoo beef. J Korean Soc Food Sci Nutr, 39, 709-718

5. Han MK (1997) The new food science. Hyungseul publishing, Korea, p 203

6. Kim DG, Lee SH, Kim SM, Seok YS, Sung SK (1996) Effects of packaging method on physico-chemical properties of Korean beef. J Korean Soc Food Sci Nutr, $25,944-950$

7. Moon YH, Jung IC (2011) Physicochemical properties and sensory score of Hanwoo beef loin after feeding with mugwort. J Korean Soc Food Sci Nutr, 40, 731-737

8. Moon YH (2011) Effects of feeding dietary mugwort on quality characteristics of Hanwoo beef during cold storage. J East Asian Soc Dietary Life, 21, 499-505 
9. Kang SJ, Moon YH, Park KS, Park HS, Jung IC (2010) Effect of maturity and marbling score on meat quality properties on Korean native fattening Hanwoo. J East Asian Soc Dietary Life, 20, 248-253

10. KFDA (2015) Food code. Korean Food \& Drug Administration. Seoul, Korea

11. Demeyer D.I, Vandekerckhove P, Moermans R (1979) Compounds determining $\mathrm{pH}$ in dry sausage. Meat Sci, 3, 161-164

12. Shin HY, Ku KJ, Park SK, Song KB (2006) Use of freshness indicator for determination of freshness and quality change of beef and pork during storage. Korean J Food Sci Technol, 38, 325-330

13. Byun MW, Kwon JH, Cho HO, Lee MK, Kim JG (1985) Physicochemiacal changes of gamma-irradiated chicken. Korean J Food Sci Technol, 17, 186-191

14. Rho JH, Kim MH, Song HN (2007) A study on the quality characteristics of brand and non-brand korean beefs. Korean J Food Cookery Sci, 23, 187-194 